\title{
Impaired reproduction in transgenic mice overexpressing $\gamma$-aminobutyric acid transporter I (GAT1)
}

\author{
Jia Hua HU ${ }^{1, *}$, Jin Fu ZHANG ${ }^{2, *}$, Ying Hua MA ${ }^{1}$, Jie JIANG ${ }^{1}$, Na YANG ${ }^{1}$, Xin Bo LI $^{3}$, Zhi Guang YU \\ $\mathrm{CHI}^{4}$, Jian FEI ${ }^{1,5^{* * *}}$, Li He GUO ${ }^{1, * *}$ \\ ${ }^{1}$ Laboratory of Molecular Cell Biology, Institute of Biochemistry and Cell Biology, Shanghai Institutes for Biological \\ Sciences, Chinese Academy of Sciences, Shanghai 200031, China. \\ ${ }^{2}$ Department of Urology, Tongji Hospital, Tongji University, 389 Xincun Road, Shanghai 200065, China. \\ ${ }^{3}$ New Drug R \& D Center, North China Pharmaceutical Group Corporation, 388 Heping East Road, Shijia \\ Zhuang 050015, Hebei, China. \\ ${ }^{4}$ School of life sciences, Fudan University, 220 Handan Road, Shanghai 200433, China. \\ ${ }^{5}$ Shanghai Research Center for Biomodel Organism, Shanghai 201203, China.
}

\begin{abstract}
It is well documented that $\gamma$-aminobutyric acid (GABA) system existed in reproductive organs. Recent researches showed that $\mathrm{GABA}_{\mathrm{A}}$ and $\mathrm{GABA}_{\mathrm{B}}$ receptors were present in testis and sperm, and might mediate the acrosome reaction induced by GABA and progesterone. GABA transporter I (GAT1) also existed in testis and sperm, but its physiological function was unknown. In the present study, we used GAT1 overexpressing mice to explore GAT1 function in male reproductive system. We found that the expression level of GAT1 continuously increased in wild-type mouse testis from 1 month to 2 months after birth. GAT1 overexpression in mouse affected testis development, which embodied reduced testis mass and slowed spermatogenesis in transgenic mice. Moreover, transgenic mice showed increase of the percentage of broken sperm. The further study revealed that the reproductive capacity was impaired in GAT1 overexpressing mice. In addition, testosterone level was significantly low in transgenic mice compared with that in wild-type mice. Our findings provided the first evidence that abnormal expression of GAT1 could result in dysgenesis, and indicated that GAT1 might be therapeutically targeted for contraception or dysgenesis treatment.
\end{abstract}

Keywords: GABA, GAT1, testes, sperm, reproduction, transgenic.

\section{INTRODUCTION}

$\gamma$-aminobutyric acid (GABA) is the principal inhibitory neurotransmitter in central nervous system (CNS) and has a widespread distribution in the mammalian brain[1]. It acts postsynaptically on ionotropic $\mathrm{GABA}_{\mathrm{A}}$ and metabotropic $\mathrm{GABA}_{\mathrm{B}}$ receptors to induce neuronal inhibition. The efficient termination of GABA transmission is depended on high-affinity GABA transporters, in which GABA transporter I (GAT1) is the predominant transporter[2, 3]. GABAergic system was found in many peripheral tissues outside the CNS[4], but its function was unclear. Previous studies showed that GABA existed in testis, epididymis, seminal vesicle, sperm and oviduct [5, 6]. Moreover, GABA at relatively low concentrations $(0.5 \mu M)$ mimics the

\footnotetext{
*These authors contributed equally to this work.

${ }^{* *}$ Correspondence author: Dr. Li He GUO

Tel: 0086-21-54921392, Fax: 0086-21-54921391,

E-mail: mhzhang@sunm.shcnc.ac.cn.
}

effect of progesterone to induce the acrosome reaction in human spermatozoa[7]. Recent researches showed that $\mathrm{GABA}_{\mathrm{A}}$ and $\mathrm{GABA}_{\mathrm{B}}$ receptors were existed in rat testis and sperm[7-9], and these receptors might mediate the acrosome reaction induced by GABA and progesterone [10-12]. The findings suggested that GABA and its receptors played an important role in reproductive system.

GABA transporters are also very important in the regulation of the magnitude and duration of the action of GABA. GABA uptake was detected in human spermatozoa suggesting the presence of a high-affinity GABA transporter protein[13, 14]. Recently, GAT1 was found existing in the testis and sperm of rat and mouse[15, 16]. We have generated transgenic mice overexpressing GAT1 in mouse testis and found that testicular morphology was abnormal in these mice[15]. In the present study, we showed that GAT1 overexpression functionally affected reproduction in mice. 


\section{MATERIALS AND METHODS}

\section{Animals}

The GAT1 overexpressed transgenic mice and wild-type littermates were developed as described[15]. TG1, as used throughout this manuscript, refers to homozygotes with GAT1 transgene, while WT (wild-type) refers to littermate mice without GAT1 transgene. Mice were group housed in plastic mouse cages $(<4$ mice per cage) with free access to standard rodent chow and water. The colony room was maintained at $22 \pm 2{ }^{\circ} \mathrm{C}$ with a $12 \mathrm{~h}: 12 \mathrm{~h}$ light:dark cycle. All the experimental protocols were performed in compliance with the National Institutes of Health guidelines for the care and use of animals and were approved by the local Animal Care and Use Committee.

\section{Comparative RT-PCR analysis}

Testis samples were removed from male mice after cervical dislocation. Total RNA was extracted with Trizol reagent (GIBCO BRL) as detailed by the manufacturer. RNA integrity was identified by formaldehyde-electrophoresis. RNA sample was thoroughly

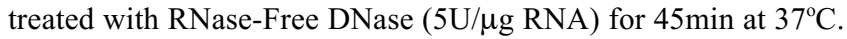
After purified, RNA sample was performed reverse-transcription with a RT kit (GIBCO BRL).

Selective primers for GAT1 cDNA were designed (CHIP1: 5'ACCAAGCTTAGGCTGCAAAGCTGCTG3', CHIP4: 5'AGGCCTTTGAACATGGGCGCCAG3'). Androgen receptor primers (AR1: 5'CCCACATCAGAGGCCCCACAG3', AR2: 5'TCCAATGCTTCCACACCCAATC3') were used to identify its expression in transgenic mice. Meanwhile, GAPDH cDNA was detected by PCR as an internal standard with primers: 5'-ACGACCCCTTCATTGACC-3' (forward) and 5'-CCAGTGAGCTTCCCGTTCAGC-3' (reverse), which spanned 588bp nucleotides within the coding sequence for GAPDH. Resultant GAPDH RTPCR products were referred to quantify the expression level of target products.

The PCR was performed initially by denaturing template DNA at $95^{\circ} \mathrm{C}$ for $5 \mathrm{~min}$, followed by minimized cycles of $94{ }^{\circ} \mathrm{C}$ for $45 \mathrm{sec}, 60$ ${ }^{\circ} \mathrm{C}$ for $45 \mathrm{sec}$ and $72{ }^{\circ} \mathrm{C}$ for $1 \mathrm{~min}$. Amplified DNA fragments were separated by agarose gel (1.2\%). Relative intensities of the products were estimated with Molecular Imager FX (BIO-RAD).

\section{Histology analysis}

Testis examination. Mice aged 1 month were anesthetized and perfused with $4 \%$ paraformaldehyde in PBS. After that, testis were removed and then dehydrated through graded ethanol and cleared with xylene, subsequently embedded in paraffin. $7 \mu \mathrm{m}$ thick paraffin-sections were cut on Leitz microtome. Slides were stained with haematoxylin and eosin, then examined and photographed under Leica microscope. The number of the seminiferous tubules with spermatozoa or without spermatozoa was recorded, and the percentage of the seminiferous tubules with spermatozoa was calculated. Two sections per mouse from both wild-type mice $(n=3)$ and transgenic mice $(n=3)$ were measured and the data were analyzed statistically.

Sperm examination. Adult mice were sacrificed by cervical dislocation. Sperm was gently released in $\mathrm{BWW}$ buffer (containing in g/L: $\mathrm{NaCl}$ 5.54; $\mathrm{KCl} 0.356 ; \mathrm{CaCl}_{2} \cdot 2 \mathrm{H}_{2} \mathrm{O} 0.250 ; \mathrm{KH}_{2} \mathrm{PO}_{4}$ 0.162; $\mathrm{MgSO}_{4} \cdot 7 \mathrm{H}_{2} \mathrm{O} 0.294 ; \mathrm{NaHCO}_{3} 2.1$; glucose 1.0 ; Sodium pyruvid acid 0.03 ; BSA 3.5 ; and $60 \%$ Syrup of sodium lactic acid $3.7 \mathrm{ml} / \mathrm{L}$ ) from the caudal epididymis of wild-type and transgenic mice using mechanical methods. Sperm sample was centrifuged and sperm was suspended in BWW buffer. Then, the sperm sample was smeared on slides and examined under Leitz microscope immediately. Sperm slides were photographed after they were dried. 1000-1200 sperms per mouse from both wild-type mice $(n=5)$ and transgenic mice $(n=7)$ were counted (regardless of sperm tail). The percentage of broken sperm was calculated and analyzed statistically.

\section{Reproduction analysis}

Male transgenic mice and wild-type mice aged 2-3 months were used to mate with female wild-type mice aged 2-3 months respectively. Male transgenic mice and wild-type mice aged 5-7 months were also used to mate with female wild-type mice aged 2-3 months respectively. The vaginal plug was checked in each female mouse. The number of gestation of female mice was recorded and the percentage of gestation was calculated in each group. The sibling size was also recorded and analyzed statistically in each group.

\section{Testosterone concentration analysis}

Blood samples were obtained by retro-orbital sinus bleeding. The concentration of testosterone was assayed with Wallac AutoDELFIA $^{\mathrm{TM}}$ Testosterone kit according to the protocol detailed by the manufacturer (PerkinElmer).

\section{RESULTS}

\section{The development of testis in GAT1 overexpressing mice}

By RT-PCR, the expression level of GAT1 was detected in the process of testis development. Results showed that GAT1 level was continuously increased in mouse testis from 1 month to 2 months after birth. The expression level of GAT1 in 1.5-mon-old and 2-mon-old mouse testis was about two times and three times higher respectively compared with that in 1-mon-old mouse testis (Fig 1a), which suggested that GAT1 might be involved in the function of testis. GAT1 expression was sustained in high level in the testis of GAT1 overexpressing mice (TG1) compared with wild-type (WT) control mice from 1 month to 2 months after birth (Fig 1a). Furthermore, GAT1 overexpressing mice showed decreased testis mass at the age of 1 month, 1.5 months and 2 months (Fig 1b). We wondered whether the testis development in the GAT1 overexpressing mice was slower than that in wild-type control mice. Therefore, the spermatogenesis was examined in TG1 mice and control mice at the age of 1 month. Results showed that the number of seminiferous tubules containing spermatozoa was significantly decreased in TG1 mice than that in WT mice (Fig 2a, 2b), and the statistical result was revealed in Fig 2c, which suggested that the testis development was inhibited in TG1 mice. Furthermore, the size of leydig cells was smaller in TG1 mice than that in WT mice, and the number of leydig cells was also reduced in TG1 mice (Fig 2a, 2b). In addition, the seminiferous tubules were a little abnormal and their diameter 
A

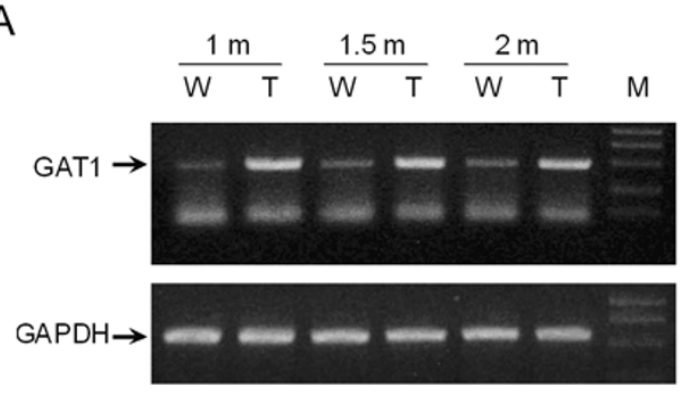

B

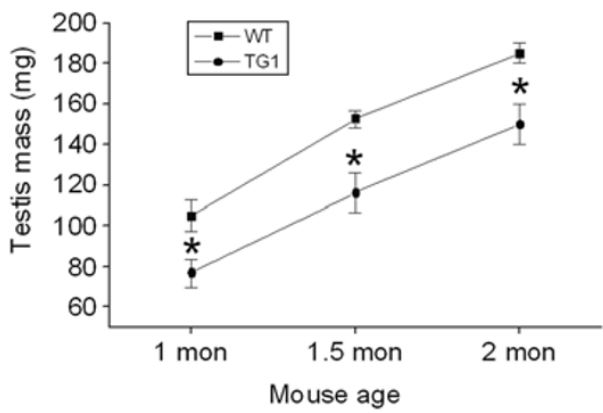

Fig 1. The development of testis in WT and TG1 mice. (A) RT-PCR analysis of GAT1 expression in WT and TG1 mice. W: wild-type; T: transgenic; m: month; M: DNA Marker (2000, 1000, 750, 500, 250, 100bp). (B) Testis mass of WT and TG1 mice. Values are presented as means \pm SEM, ${ }^{*}$ < $<0.05$ (one-way ANOVA). $\mathrm{n}=6-10$ for each group.

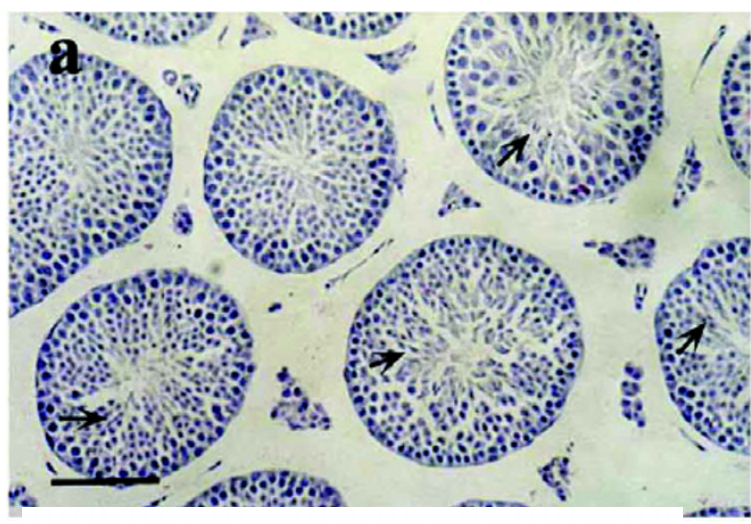

C

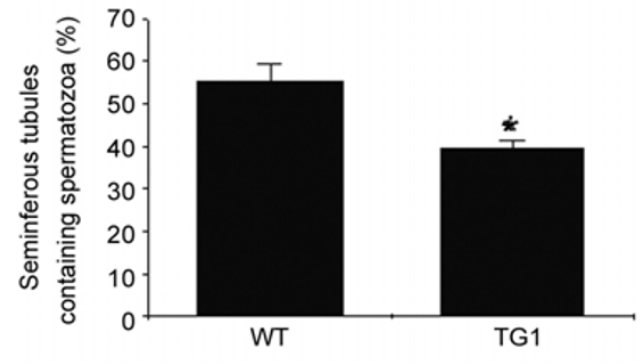

was slightly small in TG1 mice compared with WT control mice (Fig 2a, 2b). The data indicated that GAT1 overexpression affected the development of mouse testis.

\section{Increase of broken sperm in GAT1 overexpressing mice}

Previous observations in testis showed that there were fewer spermatids and spermatozoa in seminiferous tubules in adult TG1 mice than that in adult WT mice. In the present study, we found that the number of broken sperm was significantly more in TG1 mice than that in WT mice (Fig 3a, 3b). The percentage of broken sperm was assessed statistically. It was $4.6 \%$ in WT mice and $38.2 \%$ in

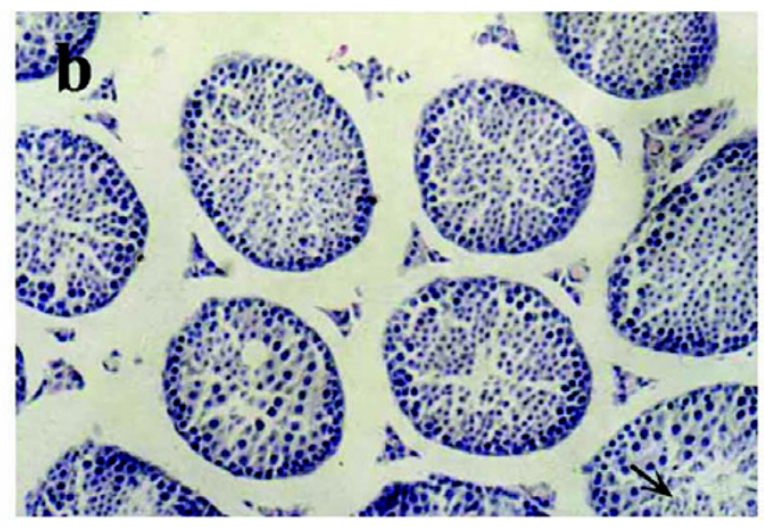

Fig 2. Spermatogenesis in WT and TG1 mice aged 1 month. (a) Seminiferous tubules of WT mice. (b) Seminiferous tubules of TG1 mice. Seminiferous tubules containing spermatozoa was indicated by arrows. Scale bar, $80 \mu \mathrm{m}$. (c) Statistical result of a and $\mathbf{b}$. Values are presented as means \pm SEM, ${ }^{*} \mathrm{p}<0.05$ (one-way ANOVA). $n=3$ for each group.

TG1 mice (Fig 3c). These observations indicated that the quantity of normal sperm was dramatically decreased in TG1 mice compared with that in WT mice.

\section{Impaired reproduction in GAT1 overexpressing mice}

To explore whether the reproductive capacity was impaired in transgenic mice, male transgenic mice and wildtype mice aged 2-3 months were used to mate with female wild-type mice aged 2-3 months. The percentage of female mice of gestation mating with male wild-type mice was $91.7 \%$ while that mating with male transgenic mice was only $53.3 \%$ (Fig $4 \mathrm{a}$ ). Furthermore, the reproductive 

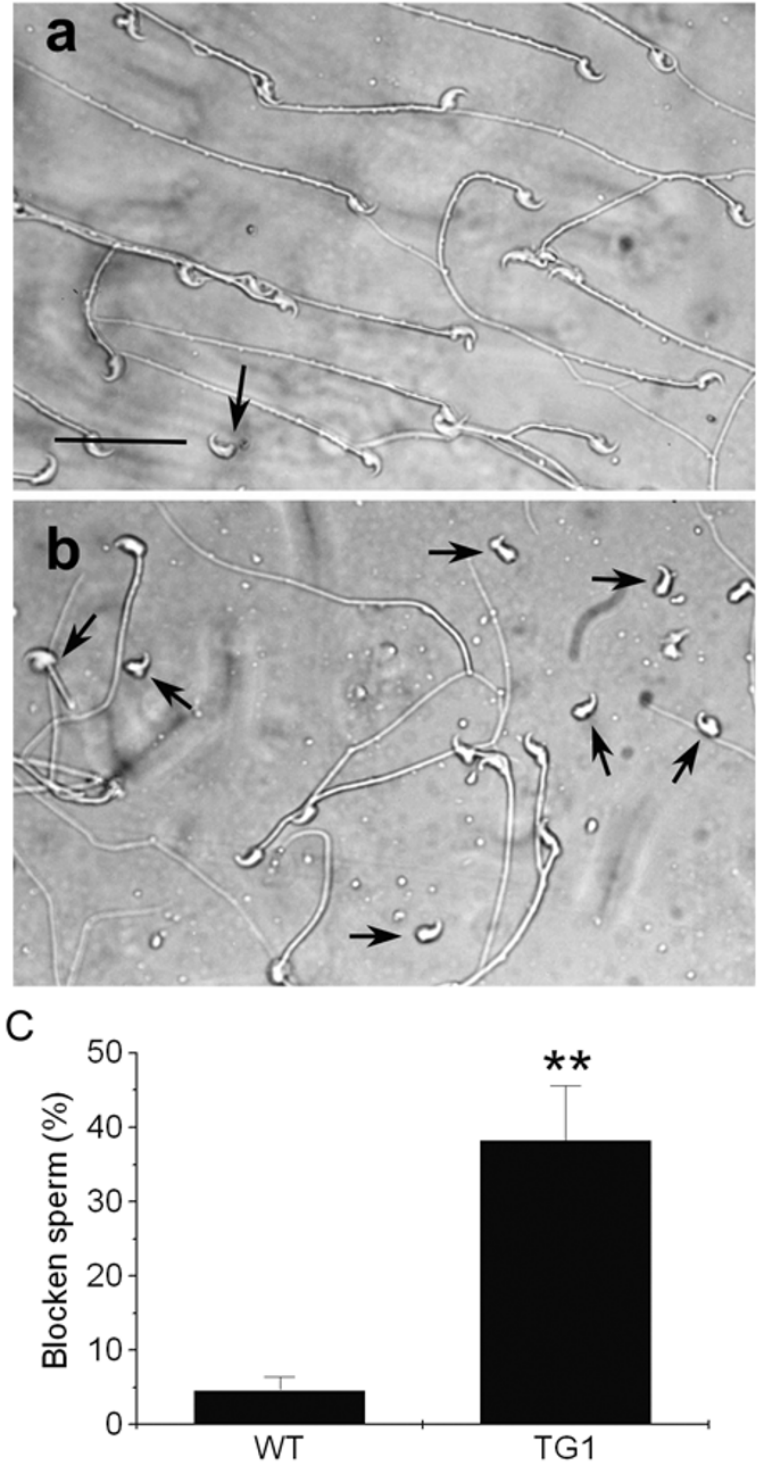

Fig 3. Sperm morphology of adult WT and TG1 mice. (a) Sperm of WT mice. (b) Sperm of TG1 mice. Broken sperms were indicated by arrows. Scale bar, $40 \mu \mathrm{m}$. (c) Statistical result of $\mathbf{a}$ and $\mathbf{b}$. Values are presented as means $\pm \mathrm{SEM},{ }^{* *} \mathrm{p}<0.01$ (one-way ANOVA). $\mathrm{n}=5$ for WT mice, $\mathrm{n}=7$ for TG1 mice.

capacity was detected in elder male transgenic mice. Results showed that $88.9 \%$ female mice were gestated after mating with male wild-type mice, but the percentage was only $33.3 \%$ for male transgenic mice (Fig 4a). These data suggested that reproductive capacity was impaired in male GAT1 overexpressing mice, although male transgenic mice and wild-type mice showed the same sibling size (Fig 4b).

\section{Decreased testosterone level in GAT1 overexpressing mice}
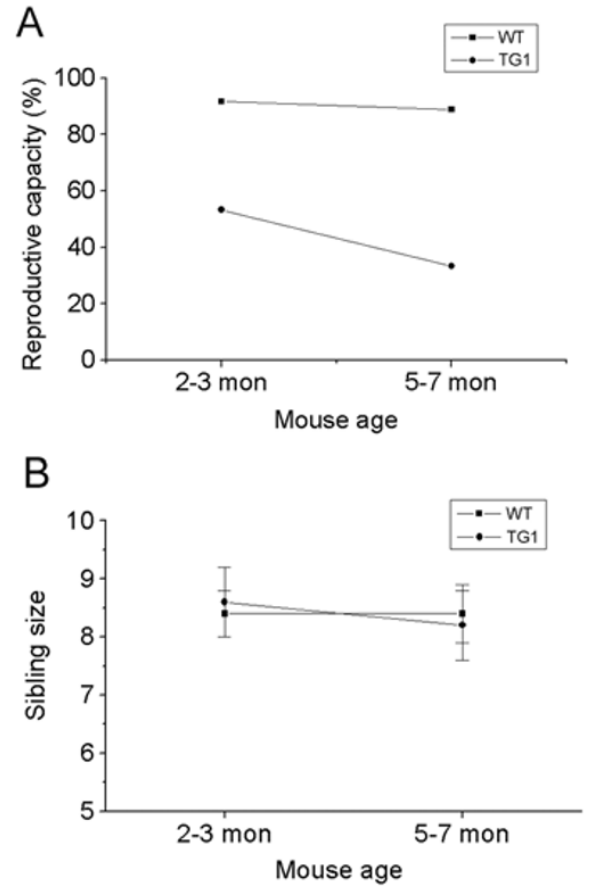

Fig 4. Reproductive capacity in WT and TG1 mice. (A) The percentage of gestation of female mice after their mating with male WT and TG1 mice. (B) The sibling size for each gestated female mice. Values are presented as means \pm SEM, $n=6-11$ for each group.

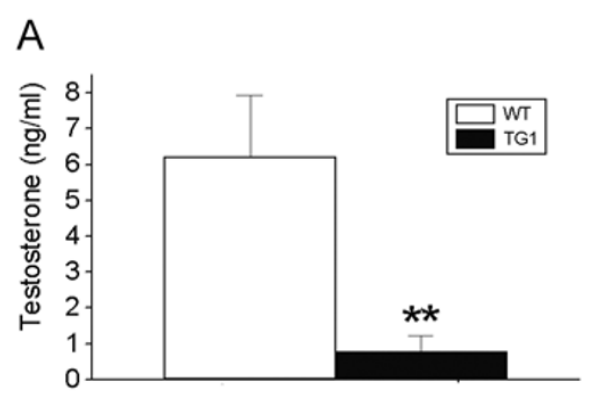

B

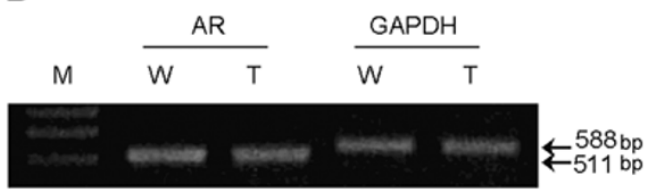

Fig 5. Testosterone concentration and androgen receptor (AR) expression in WT and TG1 mice. (A) Testosterone concentration. Values are presented as means $\pm \mathrm{SEM},{ }^{* *} \mathrm{p}<0.01$ (one-way ANOVA). $\mathrm{n}=12$ for each group. (B) RT-PCR analysis of AR expression. W: wild-type; T: transgenic; M: DNA Marker (2000, 1000, 750, 500, 250, 100bp).

The concentration of testosterone in blood was tested to explore whether the secretion of testosterone was affected in transgenic mice, since leydig cells were abnor- 
mal in TG1 mice (Fig 2a, 2b). The result showed that testosterone level was significantly decreased in blood of TG1 mice compared with that of WT mice (Fig 5a). But the expression of androgen receptor was not altered in the testis of TG1 mice compared with that in the testis of WT mice (Fig 5b). These data indicated that the level of androgen signaling was reduced in TG1 mice.

\section{DISCUSSION}

GAT1 overexpressing mice were generated to reveal that abnormal expression of GAT1 could affect reproduction and lead to infertility. Since GABA is a neurotrophic factor in CNS[17], it may also be a trophic factor in testis. GAT1 overexpression might result in low GABA concentration in the testis of transgenic mice, and then inhibited the testis development in transgenic mice (Fig 2). In adult TG1 mice, the testis morphology was also affected as previously reported[15]. In the present study, we also showed that the percentage of broken sperm in TG1 mice was significantly high compared with that in WT mice (Fig 3), although there was a few broken sperm in the sperm sample of WT mice, which might result from the collection of sperm sample. It was interesting to find that the level of testosterone in blood of TG1 mice was significantly lower than that in blood of WT mice (Fig 5a). As the leydig cells were abnormal in TG1 mice (Fig 2), it was reasonable to find that fewer testosterone was secreted by leydig cells of TG1 mice. Low testosterone concentration might influence reproduction in transgenic mice. In addition, the reproductive capacity analysis showed that fertile percentage of male TG1 mice was decreased compared with that of male WT mice (Fig 4a). However, the sibling size resulted from male transgenic mice was similar to that resulted from male wild-type mice (Fig 4b). The result might be due to the individual differences between TG1 mice.

As GABA could increase human sperm motility and activation[18] and induce the acrosome reaction in human spermatozoa[19], it was speculated to be a physiological regulator of sperm function. We supposed GAT1 was involved in sperm function since GAT1 regulated the action of GABA and it was present on rat and mouse sperm [16, unpublished data]. Moreover, GAT1 could lead to the membrane depolarization, which was important for the initiation of the sperm acrosome reaction[20, 21]. Therefore, GAT1 may play a role in acrosome reaction and abnormal expression of GAT1 may affect the sperm function and lead to infertility.

In conclusion, the present study provided the first evidence that GAT1 overexpression leaded to dysgenesis, and gave a new idea in clinical treatment of infertility and in contraception.

\section{ACKNOWLEDGEMENTS}

We gratefully acknowledge Mrs. Xi Xia Zhou and Mrs. Hua Duo Zhang for help on maintaining mice; Professor Da Wang for his invaluable assistance with the histological techniques; Mr. Mao Hu Zhang for help on laboratory affairs. This project was supported by foundations from Chinese Academy of Sciences and Special Funds for Major State Basic Research Development program of China (G19990539).

Received, Feb 13, 2003

Revised, Aug 7, 2003

Accepted, Aug 12, 2003

\section{REFERENCES}

1 Krnjevic K. Chemical nature of synaptic transmission in vertebrates. Physiol Rev 1974; 54:418-40.

2 Radian R, Ottersen OP, Mathisen-Storm J, Gastel M, Kanner BI Immunocytochemical localization of the GABA transporter in rat brain. J Neurosci 1990; 10:1319-30.

3 Pietrini G, Suh YJ, Edelmann L, Rudnick G, Caplan MJ The axonal $\gamma$-aminobutyric acid transporter GAT-1 is sorted to the apical membranes of polarized epithelial cells. J Biol Chem 1994; 269:4668-74.

4 Erdö SL, Wolff JR. $\gamma$-aminobutyric acid outside the mammalian brain. J Neurochem 1990; 54:363-72.

5 Erdö SL, Nemet L, Szporny L. The occurrence of GABA in vas deferens, prostate, epididymis, seminal vesicle and testicle of the rat. Acta Biol Hung 1983; 34:435.

6 Orensanz LM, Fernandez I, Martin del Rio R, Storm-Mathisen J. Gamma-aminobutyric acid in the rat oviduct. Adv Biochem Psychopharmacol 1986; 42:265-74.

7 Castelli MP, Ingianni A, Stefanini E, Gessa GL. Distribution of $\mathrm{GABA}(\mathrm{B})$ receptor mRNAs in the rat brain and peripheral organs. Life Sci 1999; 64:1321-8.

$8 \mathrm{He} \mathrm{XB}, \mathrm{Hu} \mathrm{JH}, \mathrm{Wu} \mathrm{Q}$, Yan YC, Koide SS. Identification of $\mathrm{GABA}_{\mathrm{B}}$ receptor in rat testis and sperm. Biochem Biophys Res Commu. 2001; 283:243-7.

$9 \mathrm{Hu} \mathrm{JH}$, Yan YC. Identification of gammal subunit of GABA(A) receptor in rat testis. Cell Res 2002; 12:33-7.

10 Shi QX, Roldan ER. Evidence that GABAA-like receptor is involved in progesterone-induced acrosome reaction exocytosis in mouse spermatozoa. Biol Reprod 1995; 52:373-81.

11 Calogero AE, Burrello N, Ferrara E, Hall J, Fishel S, D'Agata R. Gamma-aminobutyric acid (GABA) A and B receptors mediated the stimulatory effects of GABA on the human sperm acrosome reaction: Interaction with progesterone. Fertil Steril 1999; 71: 930-6.

$12 \mathrm{Hu} \mathrm{JH}, \mathrm{He} \mathrm{XB}, \mathrm{Wu}$ Q, Yan YC Koide SS. Biphasic effect of GABA on rat sperm acrosome resction: involvement of GABA (A) and GABA(B) receptors. Arch Androl 2002; 48: 369-378.

13 Aanesen A, Fried G, Andersson E, Gottlieb C. Evidence for gamma-aminobutyric acid specific binding sites on human spermatozoa. Hum Repeod 1995; 10:1885-90. 
14 Aanesen A, Fried G, Andersson E, Gottlieb C. Carrier-mediated $\gamma$-aminobutyric acid uptake in human spermatozoa indicating the presence of a high-affinity $\gamma$-aminobutyric acid transporter protein. Biol Reprod 1996; 54:841-6.

15 Ma YH, Hu JH, Zhou XG, Mei ZT, Fei J, Guo LH. $\gamma$-aminobutyric acid transporter (GAT1) overexpression in mouse affects the testicular morphology. Cell Res 2000; 10:59-69.

$16 \mathrm{Hu} \mathrm{JH}, \mathrm{He}$ XB, Yan YC. Identification of $\gamma$-aminobutyric acid transporter (GAT1) on the rat sperm. Cell Res 2000; 10:51-8.

17 Var ju P, Katarova Z, Madarasz E, Szabo G. GABA signaling during development: new data and old questions. Cell Tissue Res 2001; 305:239-46.

18 Calogero AE, Hall J, Fishel S, Green S, Hunter A, D'Agata R.
Effects of gamma- aminobutyric acid on human sperm motility and hyperactivation. Mol hum Reprod 1996; 2:733-8.

19 Shi QX, Yuan YY, Roldan ER. Gamma-Aminobutyric acid (GABA) induces the acrosome reaction in human spermatozoa. Mol Hum Reprod 1997; 3:677-83.

20 Mager S, Naeve J, Quick M, Labarca C, Davidson N, Letter HA. Steady states, charge movements, and rates for a cloned GABA transporter expressed in Xenopus oocytes. Neuron 1993; 10: 177-88.

21 Florman HM, Arnoult C, Hazam IG, Li C, Christine MB, O'Toole. A perspective on the control of mammalian fertilization by egg-activated ion channels in sperm: a tale of two channels. Biol Reprod 1998; 59:12-6. 